\title{
Embolia Cutis Medicamentosa - A Case Report
}

\author{
Shiliveri Sadhan Siddardha ${ }^{1}$, Kolluru Karthik Raja르, Amrutha Garikapati³, Sameera Dronamraju ${ }^{4}$, Sunil Kumar ${ }^{5}$ \\ 1,2, 3, 4,5 Department of General Medicine, Jawaharlal Nehru Medical College, Datta Meghe Institute of Medical Sciences \\ (Deemed to Be University), Wardha, Maharashtra, India.
}

\section{INTRODUCTION}

Embolia cutis medicamentosa is a rare complication of intramuscular injury that leads to varying degrees of necrosis of the skin and subcutaneous tissue. In 1924, embolia cutis medicamentosa or Nicolau syndrome (NS) was first portrayed after an intragluteal injection of bismuth salts was given for the treatment of syphilis but it has now been documented with several drugs. (Murthy et al., 2007) ${ }^{1}$.

According to one hypothesis, embolia cutis medicamentosa occurs when an intramuscular drug is accidentally injected into the arterial lumen or wall, leading to vessel thrombosis, subcutaneous tissue and muscle necrosis (Senel et al., 2010) ${ }^{2}$. Necrosis develops after hyperemia, skin discoloration usually associated with severe pain and wide inflammatory livedoid dermatitis and haemorrhagic patch at the injection site (Hamilton et al., 2008) ${ }^{3}$. Severe cases may take an immediate clinical course and anticipate to death.

\section{PRESENTATION OF CASE}

A 42 years brought to emergency room in unconscious state since $1 \mathrm{hr}$. In view of poor Glasgow Coma Scale (GCS) and falling saturation, patient was intubated and taken on mechanical ventilation support. After stabilisation, patient was shifted to intensive care unit. Patient had history of fever with chills since 4 days, rash on left thigh since 1 day, breathlessness on exertion since 12 hours. She had no history of chest pain, palpitations. No history of headache, vomiting, seizures. None of bleeding manifestations were noted. Patient was previously admitted in a private hospital with the complaints of fever, where she received 2 doses of intramuscular injections on left buttock prior to the development of rash (Figure 1). However, proper details (prescription / documents) were not available with the relatives.

On examination she was mesomorphic, afebrile, had pulse rate of $120 \mathrm{bpm}$, blood pressure was 60 systolic. She had cold and clammy extremities. Chest auscultation reveals bilateral fine crepitations, pupil measures $5 \mathrm{~mm}$ bilaterally and sluggishly reactive to light. Local examination reveals blackish discoloration of skin with multiple bullous formation over left buttock extending to anterior thigh, coin shaped small rash over pelvic region.

Lab Investigations revealed the following values. Haemoglobin $(\mathrm{Hb})-10.3 \mathrm{~g} / \mathrm{dL}$, mean corpuscular volume (MCV) - 89 / cu.micron, white blood cells (WBC) - 13500 / $\mathrm{mm}^{3}$, platelet count - $11000 / \mathrm{mm}^{3}$, urea $101 \mathrm{mg} \%$, creatinine $3.0 \mathrm{mg} \%$, sodium 126 meq / potassium 4.9 meq / alkaline phosphatase $233 \mathrm{IU} / \mathrm{L}$, alanine transaminase (ALT) $23 \mathrm{IU} / \mathrm{L}$, aspartate aminotransferase (AST) 54, total protein $4.2 \mathrm{gm} \%$, total bilirubin $6.7 \mathrm{mg} \%$, RBS 254, magnesium $3.4 \mathrm{mmol} / \mathrm{L}$, arterial blood gas (ABG) s / o metabolic acidosis. Her electrocardiogram (ECG) s / o sinus tachycardia with $\mathrm{S}_{1} \mathrm{Q}_{3} \mathrm{~T}_{3}$ pattern. Ultrasonography (USG) abdomen and pelvis shows normal study. USG local site was done suggestive of abnormally thickened subcutaneous tissue with streaks of anechoic strands within, showing increased vascularity. Colour Doppler revealed changes of cellulitis in left outer and upper quadrant of gluteal region with few sub centimetric lymph nodes in left inguinal region.

Patient received 2 doses of intramuscular injections on left buttock 1 day ago, prior to the development of rash. Based on her clinical presentation patient was diagnosed and treated as embolia cutis medicamentosa. However, patient succumbed within four hours of hospital stay due to septic emboli.
Corresponding Author: Kolluru Karthik Raja, Department of General Medicine, Jawaharlal Nehru Medical College, Datta Meghe Institute of Medical Sciences (Deemed to Be University), Wardha, Maharashtra, India.

E-mail: karthikkolluru300@gmail.com

DOI: $10.14260 / j e m d s / 2021 / 195$

How to Cite This Article:

Siddardha SS, Raja KK, Garikapati A, et al. Embolia cutis medicamentos - a case report. J Evolution Med Dent Sci 2021;10(12):910-911, DOI: 10.14260/jemds/2021/195

Submission 19-09-2020,

Peer Review 18-11-2020,

Acceptance 24-11-2020,

Published 22-03-2021.

Copyright (c) 2021 Shiliveri Sadhan Siddardha et al. This is an open access article distributed under Creative Commons Attribution License [Attribution 4.0 International (CC BY 4.0)] 


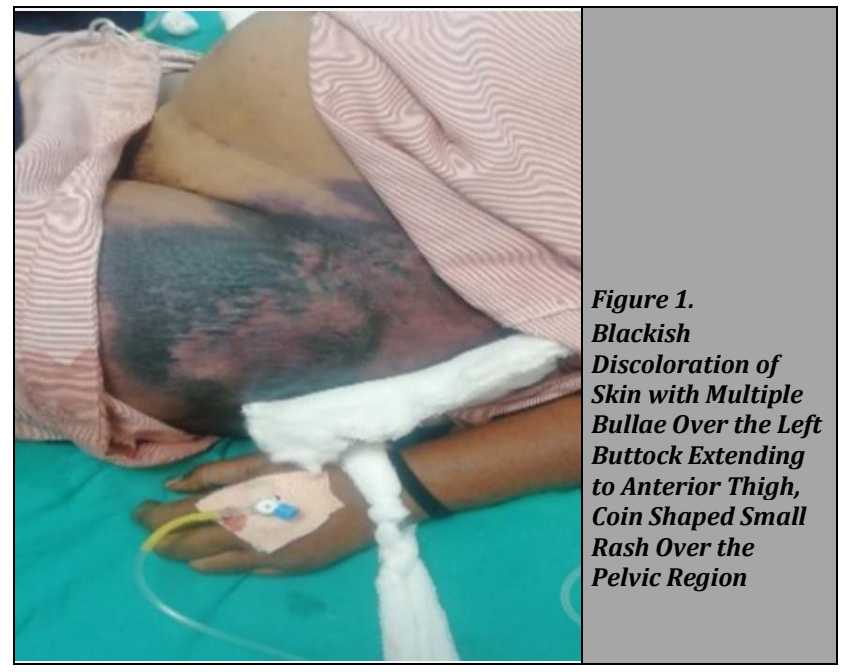

Patient was treated with injection meropenem, clindamycin, inotropes and supportive management. In view of thrombocytopenia, 4 units of platelets were given. Patient succumbed to her illness within 4 hours of hospital stay.

\section{DISCUSSION}

Embolia cutis medicamentosa is defined as a "local aseptic, cutaneous and sometimes muscular necrosis observed at the injection site of an intramuscular preparation. It usually occurs as severe pain at the injection site with the pallor due to localised reflex vasospasm, followed by erythematous maculae which typically develop after 24 hours into a livedoid purple coloured patch with haemorrhagic dendritic extensions and later becomes necrotic" (Ezzedine et al., $2004)^{4}$.

Immunologic nature for embolia cutis medicamentosa is ruled out since it is not observed after subsequent injection of the same drug. There are reports that subcutaneous injection instead of intramuscular injection is a predisposing factor. Okan et al in a study concluded that subcutaneous injection \& injury to cutaneous arteries as a probable cause leading to skin and underlying tissue necrosis. Sometimes, complete necrosis of skin occurs that mandates skin graft. More severe presentations leading to limb loss or even death has been reported (Okan et al, 2010) ${ }^{5}$.

There are many cases of embolia cutis medicamentosa in children but only few cases were reported in adults. Our patient ultimately landed in sepsis and septic shock. Death had occurred in our patient due to septic emboli.

\section{CONCLUSIONS}

Complications of intramuscular injection were not limited to widely recognised problems like anaphylaxis but also sepsis and septic shock with septic emboli leading to death of the patient as highlighted in this case report.

Financial or other competing interests: None.

Disclosure forms provided by the authors are available with the full text of this article at jemds.com.

\section{REFERENCES}

[1] Murthy SC, Siddalingappa K, Suresh T. Nicolau's syndrome following diclofenac administration: a report of two cases. Indian J Dermatol Venereol Leprol 2007;73(6):429-31.

[2] Şenel E. Nicolau syndrome. A review of the literature. Clin Med Insights Dermatol 2010;2:1-4.

[3] Hamilton B, Fowler P, Galloway H, et al. Nicolau syndrome in an athlete following intra-muscular diclofenac injection. Acta Orthop Belg 2008;74(6):860-4.

[4] Ezzedine K, Vadoud-Sayedi J, Heenen M. Nicolau syndrome following diclofenac administration. $\mathrm{Br} \mathrm{J}$ Dermatol 2004;150(2):385-7.

[5] Okan G, Canter HI. Nicolau syndrome and perforator vessels: a new viewpoint for an old problem. Cutan Ocul Toxicol 2010;29(1):70-2. 